\title{
THE MAXIMIZATION OF THE 4TH DIMENSION OF THE BUILDING SITE
}

\author{
M. Rotilio ${ }^{1 *}$, E. Laurini $^{1}$, M. Lucarelli ${ }^{1}$, P. De Berardinis ${ }^{1}$ \\ ${ }^{1}$ DICEAA, Civil, Construction-Architectural and Environmental Engineering Department, 67100 L'Aquila, Italy - (marianna.rotilio, \\ pierluigi.deberardinis)@univaq.it, elelaurini@yahoo.it, lucarelli_matteo@virgilio.it
}

Commission VI, WG VI/4

KEY WORDS: BIM, CoSIM, Safety Model, Information technology, 4D Model

\begin{abstract}
:
The aim of the contribution is to elaborate the digitalization of the construction process and of the management of the construction for both the organization of work activity and safety on the building site. The BIM methodology requires a digital implementation of construction through the creation of virtual models pertaining to the various professions involved. The CoSIM, acronym for Construction Site Information Modelling, is the application of BIM in the building site and where the federated model of the design phase materializes. The goal of the methodology developed is to obtain an elevated quality standard of the project, while trying to maximise costs and time as much as possible to favour an increase in the level of safety and security on the building site. The BSS, Building Site Safety, will allow a maximization of the safety design, not only by graphically depicting work activity but also forming a digital system for the documentation of the building site. To support this, the model is integrated with a simple plug-in which contains a library of objects to use for the designing and planning of safety on site, from general information to state of emergency warning. Thanks to the combination of the CoSIM and the BSS we can have a reduction of the variant, a reduction of time and costs due to an improved planning of work activity and allows the worker to be aware of all the modalities of procedure before entering the building site.
\end{abstract}

\section{INTRODUCTION}

In the 4.0 industry, the construction sector is undergoing a substantial change and evolution to keep up with the current innovation of technological process (Ciribini, 2012). The ECIF (European Construction Industry Federation) through the manifesto "Making BIM a Global Success", establishes that digital transformation of the industry will occur: from top to bottom with the adoption of European and national norms outlining the switch from the traditional process to BIM; from bottom to top facilitating the use of the method for all the facets of the construction chain and favouring its implementation from the educational, economic and instrumental point of view.

The European Union Public Procurement Directive (EUPPD 2014/24) invites the Member Countries to "encourage, specify or impose" the use of BIM for all projects and work publically financed in the EU starting from 2016. In Italy the transposing of the community directive is carried out through the Lgs. D. 50/2016 which poses the basis for the said "BIM Decree", namely the M. D. n. 560/2017. The aforementioned decree, together with the norms, UNI 11337 and ISO 19650 of 2018, represent a decisive step towards the great evolution of BIM in the construction industry. In particular, the ministerial decree defines the purpose, the objectives and the calendar which determines the predefined work schedule of BIM according to planned phases, to the use of the complete methodology for all types of construction. The norms of detail, instead, establish guidelines regarding characteristics and competences of BIM actors. In this way one is able to operate with standards and common rules which support the implementation of BIM.

The application of the BIM methodology requires the necessity to possess a single digital environment for collecting and sharing data related to a job (Garagnani, 2010). An ideal and virtual place which facilitates the automation of informative coordination among stakeholders, guaranteeing transparency and error reduction (Eastman, 2016). In this environment each figure and piece of information is centrally managed throughout the entire life cycle of the building, from the initial and strategic phase to the maintenance and operation phase. This permits all the participants that take part in the process to relate, sharing data as well as design, construction and maintenance choices. For a brand new project the creation of such environment constitutes a relatively simple operation. One cannot say the same when the object of intervention constitutes an existing historical building. In fact, in the case of existing buildings, detailed documents, technical specifications, user and maintenance manuals and project files are not available, and even if they do exist they do not conform to the current standard. This concept is highlighted by many authors (Inzerillo et al. 2016; Lopez et al., 2018; Penttilä et al. 2007; Tomaževič et al., 2007). Also, this such concept can produce an inefficient management of the project, loss of time and increased costs, maintenance or updating processes (Gursel et al. 2009). Brusaporci et al. (2018) highlight the presence of criticism in the application of BIM for historical heritage. In particular, Lopez et al. (2018), point out the existence of an ardent interest regarding the semi-automatic construction of H-BIM models, as also demonstrated by the two programmes, Duraark (Beetz et al., 2015) and Inception completed in the area of EU H2020 research framework program. However, in general, little interest is expressed in relation to themes such as, planning, cost estimation, analysis and simulation, residual and demolition management (Lopez et al. 2018). They attribute it to the fact that most of the bibliographies mainly deal with new buildings (Akcamete et al., 2010, Cheng et al., 2012). Such sentence is valid mostly in relation to the said "number four dimension" of the building information modeling, that is to say, the evolution of modeling throughout time. It appears at this time to be

* Corresponding author 
among the least explored and experimented by the operators. The possibility of providing digital 4D areas would contribute to the possibility of structuring constructive processes with programmatic methods capable of facilitating the work phases, reducing materials waste, managing schedules, but most of all, increasing the health and safety on the building site. Efficient communication among all the project stakeholders would maximize the efficiency of the transfer of integral information related to the artefact and would improve the use of the project, in favour of a safe constructive process and a higher level of management.

For this reason some research has been developed with the main objective consisting in the organization of methods and strategies aimed at optimizing the diverse phases of design (preliminary, definitive and execution), and the proceeding phases of completion. In particular, the virtual modeling associated with base data directly from the BIM environments, have been integrated and reutilized to rationalize the organization of the building site through new dynamic representations in 4D (3D + time) and with experimentation of a plug-in as described in the following.

\section{METHODOLOGY}

The BIM methodology (figure 1) allows an integrated management of the information flows and an updated exchange of information thanks to the common data environment (CDE). It requires the digital implementation of the construction through the creation of virtual models related to the various professionals involved.

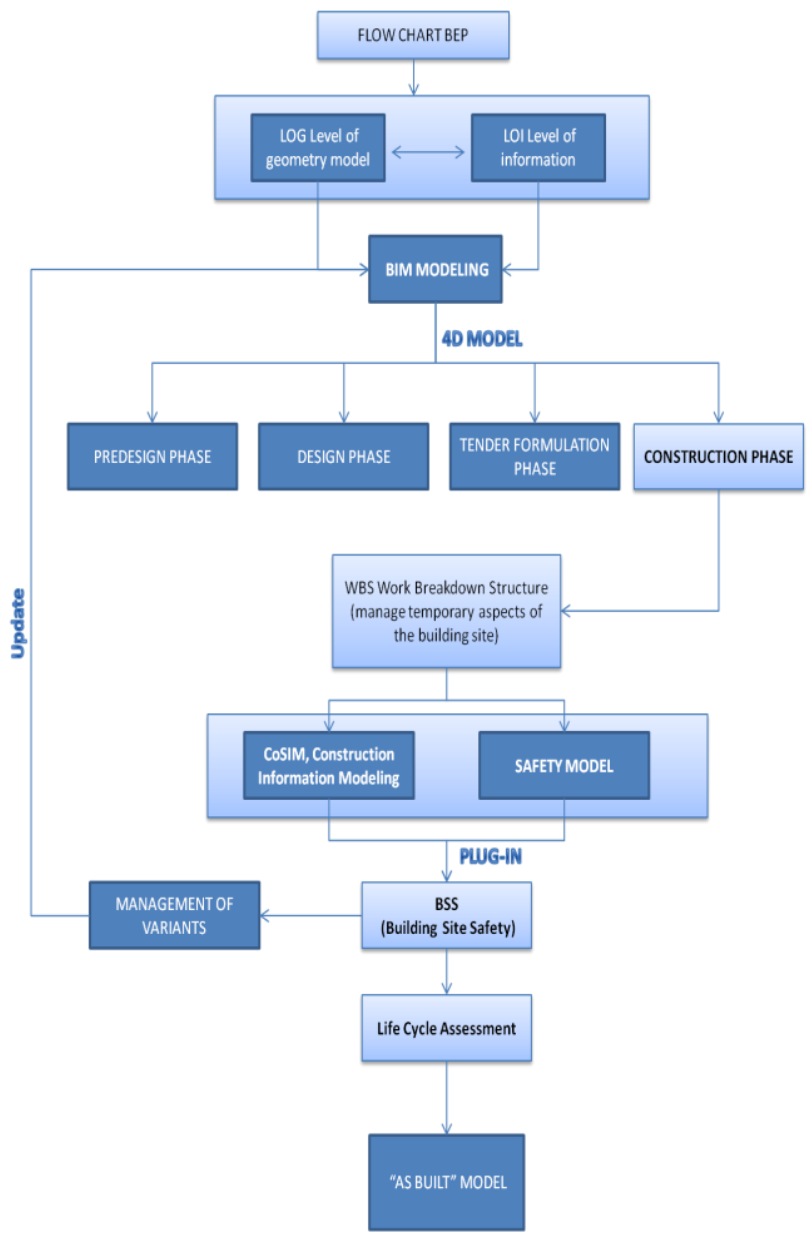

In addition to the structural, architectural and engineering models, other models exist, according to UNI 11337, determined for each phase of the scheduled work. In addition to each phase of the project pertinent LOG (Level of geometry model) and LOI (Level of information) (Lucarelli, 2019) will correspond allowing step by step production to an As Built model. The latter in particular must be carried out at the same place as the work and only after this has been completed and verified by the responsible parties will the federated model be updated (figure 2). Therefore, in order to not incur error and avoid omission of information, the As Built model (LOD 500) must not be completed in correspondence to the closing of the building site since it will be fundamental for the proceeding phase of facility management. In this area, the methodology developed has the objective of obtaining an elevated standard of project quality, in an effort to optimize costs and time as much as possible, in favour of increasing the level of safety on the building site. These three variables are tightly connected to each other since they depend directly on "time".

The 4D modeling permits designers to visualize activity correlated by the construction process. All the construction and activity connected must be given well defined starting and ending dates, tied to specific 3D components, so as to be visualized in the relative 4D model.

They can be used in the entire cycle of the project distinguishable in four specific phases; they being pre-design, design, tender formulation, and construction (Eastman et al. 2011). In this last phase the $4 \mathrm{D}$ models can be used to manage temporary aspects of the building site. Understanding where and how the operators will work for a period of time, manage work flow and safety of building site. Most of all they will allow verification that models correspond to the limitations defined by the contracted schedule and "provide remedy" to any potential deviance.

This aspect is of particular interest in the area of existing building site for the management of the variants and the relative impact (figure 3). In summary, the advantages of the 4D modeling can be summed up in greater communication of the interested parties through the visualization and comprehension of the phases; in the analysis of the workflow and use of spaces, in the improvement of the coordination of sub-contractors and among the actors; in the detailed synthesis of the constructive sequences. It is evident that depending on the timing it will be possible to define the costs and the issues relating to safety. A 4D model, after having designed a WBS (Work Breakdown Structure) and having associated its own given to timing, allows the understanding of the evolution of the building site and the continuous transformation of its conformation.

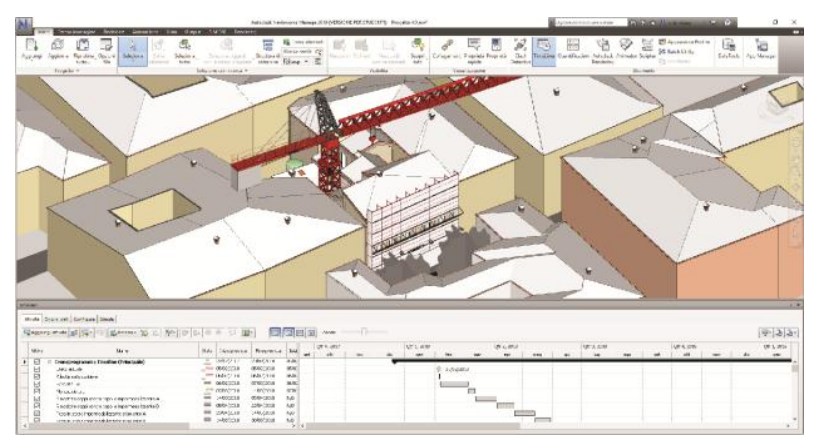

Figure 2. The management of the 4D was realized in Autodesk Navisworks thanks to the use of the federated parametric model of Autodesk Revit and the Gantt of Microsoft Project.

Figure 1. The Methodology scheme 


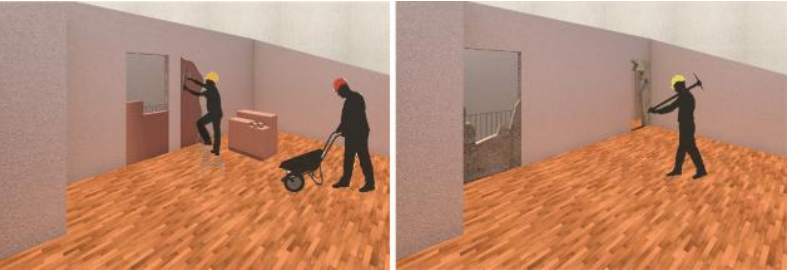

Figure 3. The variant represented the creation of two new doors and the closing of the existing ones by means of unstitch and sew.

Observing some projects in greater detail one has the possibility to fully comprehend in detail the overlapping of space-time of projects with the individualization of the risks generated from the logistics situation and space contingent.

At this point, besides the classic models, the CoSIM, Construction Site Information Modeling, is to be noted to which we add the Safety Model (Rotilio et al., 2018). The former is capable of analysing the areas relating to the implementation phase of the building process and needs to be updated at the same pace as the evolution of the building site not only for an improved ROI (return of investment) but also to better coordinate the work activity of the trades present on the building site.

\section{ANALYSIS}

In maximizing the working process in both "ON site" and "OFF site" construction sites, we consider the Gantt diagram as a fusion of two different levels: general and detailed. The former, besides displaying a timing sequence of the activity arranged according to an initial regulation/strategy, will be a synthesis of the multiple aspects aimed at eliminating interference among the work activity as much as possible and reducing the time of completion and possible problems tied to risk management.

The detailed portion will deal with the subdivision of the general in " $n$ " range, which are to respect their previously assigned schedule so that no delays arise in their own range and subsequently, in the final consignment of the work.

The term, "range", indicates a parameter block namely a container for all the information regarding that specific period of time such as activity to implement, the responsible parties of the activity, the building site operations, supply of material, the safety devices to adopt and cost control. In case of variance, facing a delay in work progress, operation will be within the range itself so as to study the specific situation and adopt the best solution among the many. Therefore, we will not proceed with a total translation of activity but reorganization of the block or range respecting the previous defined parameters. Even facing an unexpected or necessary variant we will have a maximization of procedures in particular, a saving of time, cost and effort given that a limited number of range is to be modified while the others remain invariant or as originally deployed.

To integrate this last point, the safety model could be considered as a model of parameter comprehensive of all the phases of assembly and disassembly of the provisional work related to the safety and utilization of CPP (Collective protective equipment) and PPE (Personal protective equipment) in order to contain the risk (Laurini et al., 2019). We refer to the BSS Model (Building Site Safety) integrated with a digital system for the production of the building site documentation, which currently in most cases turn out to be Photostat with the use of few attached graphics. What is important to remember is that the BIM is applicable to the full life of the building starting from the design and contraction work, proceeding to the implementation phase and terminating with the closure phase, where is foreseen (Life Cycle Assessment). During the construction phase of the project there are many positive aspects of the utilization of a federated BIM model: the planning of the work would result in being more true to reality; the building site conditions would be better in the definition of the work areas and interferences, easily pointing out risk situations; the coordination and management of human and material resources would be maximized, also thanks to the planning of supply in predefined times in order to reduce storage deposit areas on the building site. The last but not the least important positive aspect of the use of the BSS Model for recovery building sites, is the simplified and faster management of variants in the work in progress. From the modifications brought to the model we obtain automatic updating of the estimated calculations and updating of the building site in light of the introduced variants. In managing projects in the traditional process, the inspections are done in the concluding portions of planning and by sample, creating doubt and hiding error which could develop over time even with a lack of regular and extra maintenance provoking a reduction of internal comfort or even lack of security to the user. Moreover, thanks to BSS Model we will be able to "educate and safeguard" the worker until he has a $360^{\circ}$ vision of the building site in which he operates. In fact, the evaluation of the security of the building site bases itself on the analysis of the dangers and on the evaluation of the risk of the construction phases (Lucarelli et al, 2019).

\section{POTENTIAL AND EXPERIMENTATION OF THE} MODEL

The product we would like to obtain, is a simple type and easy to manage. It is a simple plug-in that has been tailor made for this purpose, which will be make it possible to communicate all the necessary information to the BIM model in order to have a new asset to the work in progress building site. The plug-in will be able to contain a library of objects, elements for space modeling and building site function: decks, scaffolding, cranes, elements for system installation and for technological aspects of the work area (figure 4, 5). Elements to be used for the designing and planning of the safety and security on site, from general information to alerts which in the simulation of building site make you notice the urgency of adopting specific DPI.

This will be integrated in the interior of the specific and unique software for the modeling of the building site and the managing of the work phases (figure 6). Default parameter families will be necessary for the model of the building site so as to hasten the completion of the model and increase data sharing.

Moreover, thanks to this, we can then obtain maximization of the construction phase and an automated and interactive management system. This system could also be updated via an application to use with a smartphone or tablet, of simple and quick operation by the user. And even more, this system, perhaps utilizing a QR code, may permit whomever periodically enters the building site or for the first time, to receive all the information he requires. Furthermore, thanks to it, a model of the building site (CoSIM) may be attainable and developed in its integral form with the other models (architectural, structural, plant, hvac) but most of all verifying their possible future interferences in the various moments in the completion of the project. Inside the plug-in there is the entire history of the model evolution with reference to the LOD utilized. In regard to the level of development, we need to reserve particular care in case of existent. 

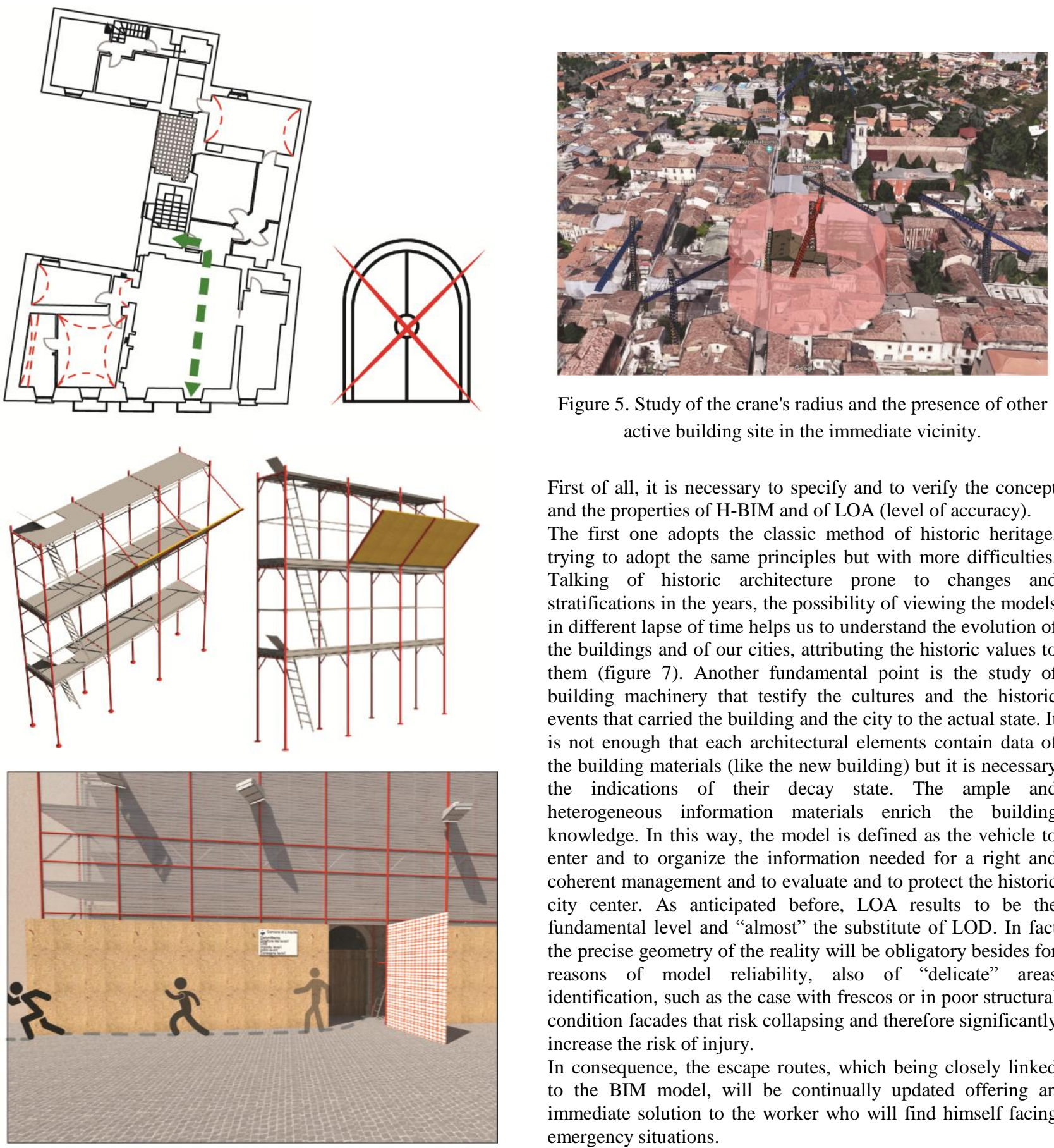

Figure 4. The historic building presents only one way of exodus. In the event that this cannot be used for various reasons such as the breaking of the door or the execution of work activities on the ground floor. The staff will use the stairs provided with the scaffolding to exit and reach the collection point.

Figure 5. Study of the crane's radius and the presence of other active building site in the immediate vicinity.

First of all, it is necessary to specify and to verify the concept and the properties of H-BIM and of LOA (level of accuracy). The first one adopts the classic method of historic heritage, trying to adopt the same principles but with more difficulties. Talking of historic architecture prone to changes and stratifications in the years, the possibility of viewing the models in different lapse of time helps us to understand the evolution of the buildings and of our cities, attributing the historic values to them (figure 7). Another fundamental point is the study of building machinery that testify the cultures and the historic events that carried the building and the city to the actual state. It is not enough that each architectural elements contain data of the building materials (like the new building) but it is necessary the indications of their decay state. The ample and heterogeneous information materials enrich the building knowledge. In this way, the model is defined as the vehicle to enter and to organize the information needed for a right and coherent management and to evaluate and to protect the historic city center. As anticipated before, LOA results to be the fundamental level and "almost" the substitute of LOD. In fact the precise geometry of the reality will be obligatory besides for reasons of model reliability, also of "delicate" areas identification, such as the case with frescos or in poor structural condition facades that risk collapsing and therefore significantly increase the risk of injury.

In consequence, the escape routes, which being closely linked to the BIM model, will be continually updated offering an immediate solution to the worker who will find himself facing emergency situations.

In this case we find ourselves facing an emergency in a historical building with only one escape route. Before beginning work, the designer, thanks to a model of the building site, packed with all the information, will elaborate the hypothetical situations which may arise during the phase of implementation. These can be of three types. The escape route cannot be used for fire, mechanical damage (in this case of the portal) or repairs.

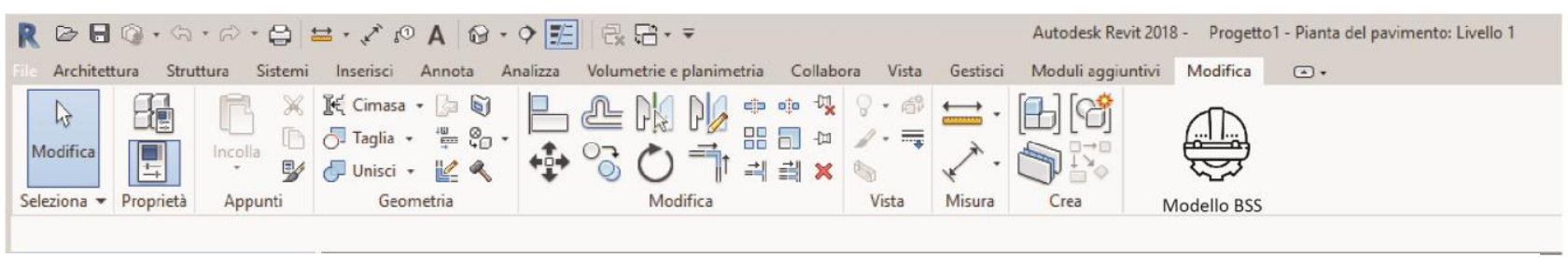

Figure 6. The introduction of the plug-in within the 3D BIM modeling software. 


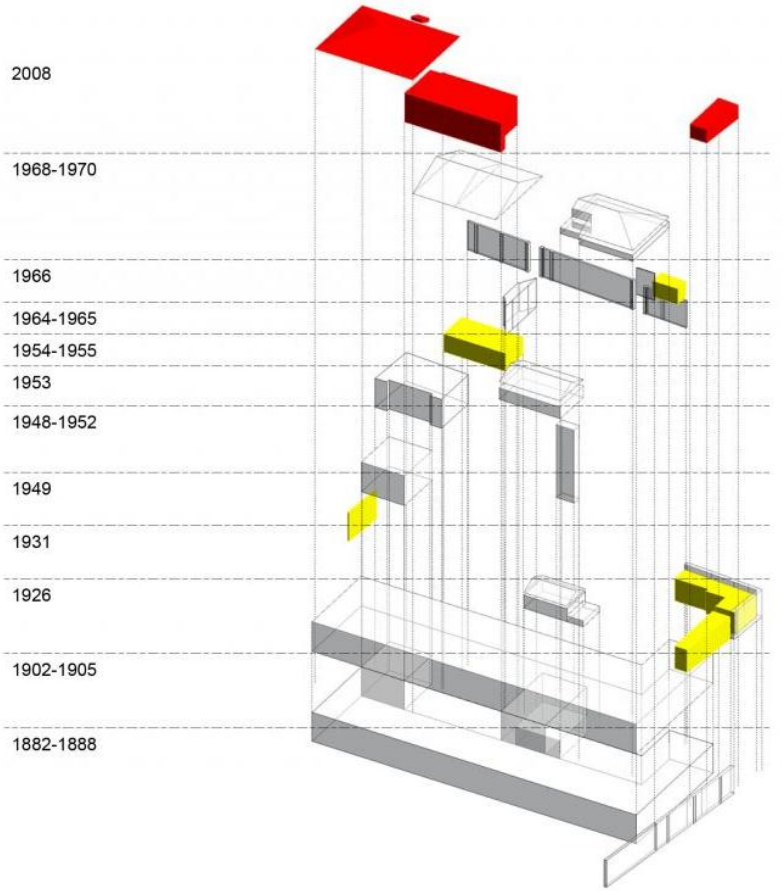

Figure 7. Analysis of the building historical evolution developed through the model

The latter will certainly occur since repairs will be carried out which will impede or make the route of escape impossible for workers. What to do?

The personnel, as demonstrated by the image (figure 4), will use the route defined and present in the model, thanks to the plugin, figure 6 , and therefore the stairs provided at deck to exit and reach the gathering point.

The transferability of the product seems immediate and the use may benefit not only the companies themselves, the actors who participate in the implementation and management of safety, but also the public administrations that could arrange executive projects of buildings and models BIM "as built", updated during the phases of detailed execution.

Furthermore, the final user would have access to an instrument for building inspection and, through a subsequent use of the building, he may benefit from precise data and information regarding the building.

\begin{tabular}{|l|c|}
\hline \multicolumn{2}{|c|}{ Main nomenclature about BIM } \\
\hline CoSim & Construction Site Information \\
BSS & Modelling \\
H-BIM & Building Site Safety \\
& Heritage Building Information \\
3D BIM & Modeling \\
4D BIM & 3D drawings with an added z-axis \\
& 3D model drawings with an added \\
CDE & "time" element \\
LOG & Common data environment \\
LOI & Level of geometry model \\
LOD & Level of information \\
LOA & Level of development \\
WBS & Level of accuracy \\
ROI & Work Breakdown Structure \\
& Return of investment \\
\hline
\end{tabular}

Table 1. BIM Nomenclature
He also could use of such information for all the building utilizations and having full awareness of how and when to intervene in order to have a building with high performance.

\section{CONCLUSIONS AND FUTURE DEVELOPMENTS OF THE RESEARCH}

The methodology proposed aims at the achievement of elevated quality standards of the project, trying to optimize costs and time as much as possible in favour of an increase in the level of safety on the building site through 4D modeling. In developing the research, the authors observed some important criticism due to the exchange of information, that is, the fact that you operate in a field with problems of interoperability among software. At international level, the tendency is aimed at overriding the said criticism, promoting the integration among the phases of preliminary design, executive implementation and management of the project through computer applications of parameter nature in achieving $\mathrm{nD}$ modeling. Today, the use of computer applications allows for integrated design but not for automated, with the transmission of data such as time, costs, quality checks and safety. In addition to the effort of the software house to create products that include not only a higher number of data but that they are truly and objectively interoperable, an effort is requested of the professionals in the sharing and passing of "actual" models to all subjects in the production chain.

Today discussions emerge mostly regarding the realization/economic point of view. However, this must not be a limit for the BIM since this would affect (unfairly) the client.

\section{ACKNOWLEDGMENTS}

M.R. defined the structure, the organization of the article and supervised it. She was also the corresponding author. M.R. and E.L. wrote the article in an equal manner. M.L. elaborated figures 1,3-7 during the research development, E.L. the figure $n$. 2 and M.R. Table n.1. The research group consisted of all the authors. In particular P.D.B was responsible for the scientific research.

The study presented in the article was developed within the research group "Production of the building industry and rational management of the construction process on site", DICEAA, University of Study of L'Aquila, Italy.

\section{REFERENCES}

Akcamete, A., Akinci, B., Garrett, J. H., 2010. Potential utilization of building information models for planning maintenance activities. Proceedings of the international Conference on Computing in Civil and Building Engineering, Nottingham, UK, 30 June-2 July 2010, 151-158.

Beetz, J., Blümel, I., Dietze, S., Fetahui, B., Gadiraju, U., Hecher, M., Krijnen, T., Lindlar, M., Tamke, M., Wessel, R., Yu, R., 2015. DURAARK: Enrichment and Preservation of Architectural Knowledge. In Edited Volume Sander Münster, Mieke Pfarr-Harfst, Marinos Ioannides, Piotr Kuroczyński and Ewald Quak (Eds.): How to manage data and knowledge related to interpretative digital $3 D$ reconstructions of Cultural Heritage?, Springer LNCS

Brusaporci, S., Trizio, I., Ruggieri, G., Maiezza, P., Tata, A., Giannangeli, A., 2018. AHBIM per l'analisi stratigrafica dell'architettura storica. Restauro Archeologico, 27(1), 112-131. 
Cheng, J. C., Ma, L. Y., 2012. BIM-based system for demolition and renovation waste quantification and planning. Proceedings of the 14th International Conference on Computing in Civil and Building Engineering (ICCCBE 2012), Moscow, Russia, 27-29 June 2012.

Ciribini, A. L., 2012. L'information modeling e il settore delle costruzioni: IIM e BIM. Maggioli Editore, Santarcangelo di Romagna (RN).

Eastman, C., Teicholz, P., Sacks, R., Liston, K., 2008. BIM Handbook - a guide to building information modeling for Owners, Managers, Designers, Engineers and Contractors, John Wiley \& Sons, Inc., New Jersey

Gursel, I., Sariyildiz, S., Akin, Ö., Stouffs, R. 2009. Modeling and visualization of lifecycle building performance assessment. Adv. Eng. Inform., 23, 396-417.

Inzerillo, L., Lo Turco, M., Parrinello, S., Santagati, C., Valenti, G. M., 2016. BIM e beni architettonici: verso una metodologia operativa per la conoscenza e la gestione del patrimonio culturale. BIM and architectural heritage: towards an operational methodology for the knowledge and the management of Cultural Heritage. Disegnarecon, 9, 161-169.

Laurini, E., Rotilio, M., Lucarelli, M., De Berardinis, P., 2019. Technology 4.0 For Buildings Management: From Building Site To The Interactive Building Book. 2nd International Conference of Geomatics and Restoration, Milan, Italy, 8-10 May 2019.

López, F. J., Lerones, P. M., Llamas, J., Gómez García Bermejo, J., Zalama, E., 2018. A Review of Heritage Building Information Modeling (H-BIM).Multimodal Technologies Interact., 2(2), 21.

Lucarelli, M., Laurini, E., and De Berardinis, P. 2019. 3D and 4D Modelling in building site working control, Int. Arch. Photogramm. Remote Sens. Spatial Inf. Sci., XLII-2/W9, 441446, https://doi.org/10.5194/isprs-archives-XLII-2-W9-4412019.

Lucarelli, M., Laurini E., Rotilio, M., De Berardinis, P., 2018. Metodo BIM: gestione dei cantieri edilizi nei centri colpiti da calamità naturali. VI Edizione Convegno ReUso, Messina, Italy 11-13 October. Gangemi Editore, Roma, ISBN: 978-88-4923659-0.

Lucarelli, M., Laurini, E., Rotilio, M., De Berardinis, P., 2019. Bep \& Mapping Process for The Restoration Building Site. 2nd International Conference of Geomatics and Restoration, Milan, Italy, 8-10 May 2019.

Penttilä, H., Rajala, M., Freese, S., 2007. Building information modelling of modern historic buildings. Proceedings of the 25th eCAADe Conference on Predicting the Future, Frankfurt am Main, Germany, 26-29 September 2007.

Rotilio, M., Laurini, E., De Berardinis, P., Cococcetta, L., 2018. Progettare la cantierizzazione in un centro storico colpito dal sisma: un caso di studio. VI Edizione Convegno ReUso, Messina, Italy 11-13 October. Gangemi Editore, Roma, ISBN: 978-88-492-3659-0.
Tomaževič, M., Lutman, M. 2007. Heritage masonry buildings in urban settlements and the requirements of Eurocodes: Experience of Slovenia. Int. J. Archit. Heritage, 1, 108-130. 